\title{
Two cases of isolated first rib fracture
}

\author{
Vikramaditya, P Pritty
}

\begin{abstract}
Isolated first rib fractures are uncommon. They are usually associated with severe blunt trauma, although other mechanisms have been suggested, these being (a) indirect trauma, (b) sudden contraction of the neck muscles, and (c) stress or fatigue fractures attributable to repeated pull of muscles. Two cases are reported of stress fracture of the first rib, who presented to the accident and emergency department. (Emerg Med f 2001;18:498-499)
\end{abstract}

Keywords: first rib fracture

\section{Case reports}

CASE 1

An 18 year old man presented to our accident and emergency (A\&E) department with a 10 day history of pain, felt medial to the right shoulder. There was no history of trauma. He does do some weight training, but did not remember any specific event or injury. The pain was associated with movement of both right and left shoulders. The pain was of moderate severity and prevented him using the right arm. There was no relief with simple analgesia. On examination, there was no deformity nor swelling around the shoulder. There was minimal supraclavicular tenderness. Movements were limited by pain although the range of passive movements was greater. Cuff stress and cuff relaxation tests were positive, and an initial diagnosis of rotator cuff injury was made.

A shoulder radiograph showed an isolated fracture of the first rib on the right side (with a normal shoulder). The patient was managed with a collar and cuff, regular analgesia and was followed up in A\&E clinic. Follow up radiographs showed a healing fracture. The patient made an uneventful recovery over four to five weeks.

CASE 2

A 12 year old girl presented to the A\&E department at a weekend, with pain on movement of the left shoulder. Initially there was no history of trauma. Although when seen in clinic, she mentioned having played rugby a few days before the onset of pain. Examination revealed minimal tenderness above the clavicle and painful shoulder movement. This patient was seen just a few days after the first case, by the same doctor, and, as the history was similar, one of the differentials was fracture of the first rib. This was confirmed when radiography was performed (fig 1). Treatment consisted of a collar and cuff and analgesia This girl was followed up in A\&E clinic. The initial radiograph was reported as no bony injury, the "fracture" diagnosed as an anoma-

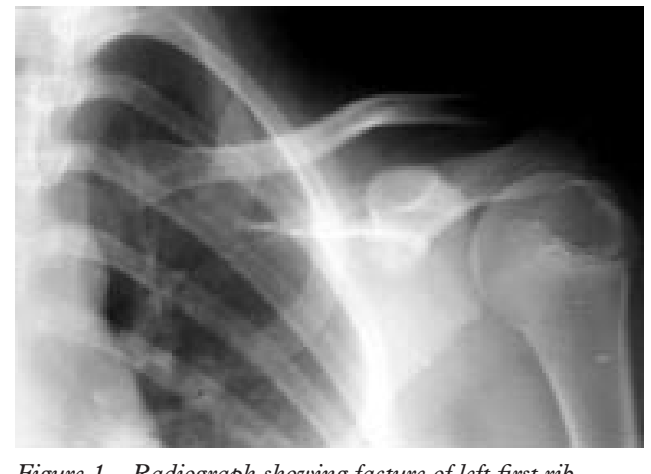

Figure 1 Radiograph showing facture of left first rib.

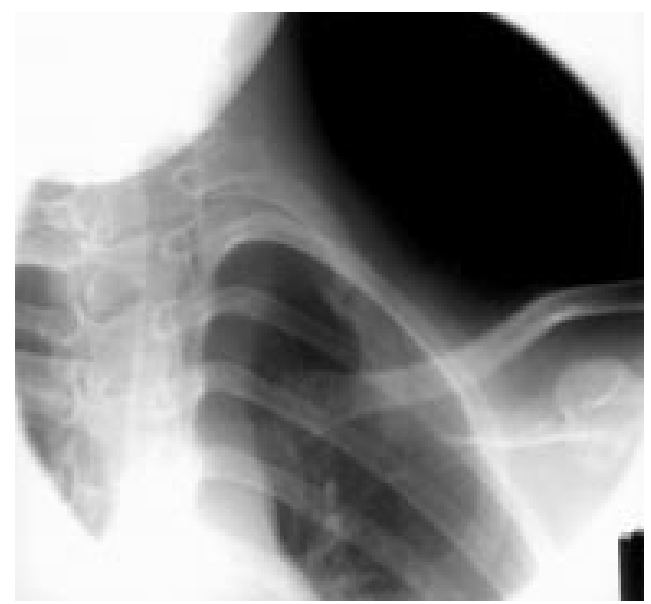

Figure 2 Radiograph showing callus formation at the fracture site.

lous articulation. ${ }^{1}$ Another radiograph six weeks later showed callus around the "anomalous articulation", which supported our earlier diagnosis of fracture (fig 2). She too has had an uneventful recovery.

\section{Discussion}

According to medical literature, fractures of the first rib are quite rare. ${ }^{23}$ The first rib is situated quite deep and most cases of traumatic first rib fractures are associated with clavicle and/or scapula fractures. The various mechanisms, associated injuries and complications have been discussed by many authors. ${ }^{24}$

Pseudoarthrosis of the first rib may be seen and usually represents a congenital defect, a normal variation or may be caused by a stress fracture. Congenital defect of ossification generally shows a smooth margin and there is no callus formation. ${ }^{1}$

Stress fracture of the first rib occurs at the weakest anatomical point, this being the groove for the subclavian artery. The bone here is subject to opposing forces because of muscular action and so repeated pulls can result in a stress fracture..$^{135-9}$
Accepted for publication 15 March 2001 
The mechanism suggested for the indirect type of fracture, is, a sudden violent contraction of the scalenus anterior muscle, combined with traction on the $\mathrm{arm}^{210}$ (a "lay back" manoeuvre while surfing leading to a "surfer's" rib would be an example). The fracture in these cases is always at the level of the subclavian sulcus, where the scalenus and the serratus exert opposite traction, and the bone is weakest. A similar mechanism occurs with sudden hyperextension of the cervical spine.

In some patients, the fracture is an incidental finding on chest radiographs. These may be asymptomatic, and hence some authors have suggested this is a developmental anomaly. ${ }^{12}$

The fracture seen in both our patients may be described as stress or fatigue fractures. In both patients, there is history of previous physical exertion, first case weight training, and the second rugby. Our patients were treated conservatively and both did well on follow up. There was no use of expensive or time consuming tests.

We report these cases to show the nonspecific history that may be associated with a fracture and that these fractures can occur in very young people. We suggest that all patients who present with history of pain in the shoulder and/or upper chest should have first rib fracture as one of the differential diagnoses. Treatment can be conservative leading to good results at little cost, with no recourse to expensive investigations.

Funding: none.

Conflicts of interest: none.

1 Keats TE. Atlas of normal roentgen variants that may simulate disease. 6th ed. St Louis: Mosby, 1996:387-9

2 Lorentzen JE, Movin M. Fracture of the first rib. Acta Orthop Scand 1976;47:632-4.

3 Mikawa Y, Kobori M. Stress fracture of the first rib in a weightlifter. Arch Orthop Trauma Surg 1991;110:121-2.

4 Mitsuo O, Yoshiaki S, Tsuneji M, Yoshikazu I. Brachial plexus palsy secondary to stress fracture of the first rib: case report. F Trauma 1994;36:128-30.

5 Chan MC, Fenton P, Conlan AA. Unusual site of spontaneous first-rib fracture: case report [see comments]. Can $\mathcal{F}$ Surg 1994;37:425-7.

6 Liew SM, Cunningham R. An unusual cause of stress frac-

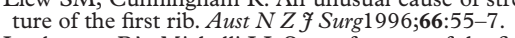

7 Lankanner PA, Michelli LJ. Stress fracture of the first rib. $\mathcal{F}$ Bone foint Surg Am 1985;67:159-60.

8 Rademaker M, Redmond AD, Barber PV. Stress fracture of the first rib. Thorax 1983;38:312-13.

9 Curran JP, Kelly DA. Stress fracture of the first rib. $A m \mathcal{F}$ Orthop 1966;8:16-18.

10 Moore RS. Fracture of the first rib: an uncommon throwing injury Injury 1991;22:149-50. 